\title{
Does the proportion of associatively related pairs modulate the associative priming effect at very brief stimulus-onset asynchronies?
}

\author{
Manuel Perea *, Eva Rosa ${ }^{1}$ \\ Departament de Metodologia, Facultat de Psicologia, Universitat de València, Av. Blasco Ibáñez 21, \\ 46010 València, Spain
}

Received 1 February 2001; received in revised form 2 August 2001; accepted 20 September 2001

\begin{abstract}
A number of experiments have shown that the magnitude of the associative priming effect increases substantially when there is a high proportion of associatively related pairs in the list when the stimulus-onset asynchrony (SOA) between prime and target is long (more than 400 $\mathrm{ms})$. In the present series of experiments we manipulated the proportion of associatively related pairs when the SOA was very brief (less than $200 \mathrm{~ms}$ ). If processing of a target word is facilitated automatically by the prior presentation of a related prime, the occurrence of priming should be unaffected by the proportion of related pairs in the list. Experiment 1 showed a robust relatedness proportion effect obtained in a double lexical decision task. Experiments 2 4 used the masked priming technique at several very short SOAs $(66,116$, and $166 \mathrm{~ms})$ in lexical decision and naming. The results showed a reliable associative priming effect in the two tasks, which did not differ as a function of the proportion of related pairs. Finally, Experiment 5 used unmasked primes at an 83-ms SOA in which the primes remained in view after the target presentation. As in Experiments 2-4, the associative effect was not modulated by the proportion of associatively related pairs. The implications of these results are discussed. (c) 2002 Elsevier Science B.V. All rights reserved.
\end{abstract}

PsycINFO classification: 2340

Keywords: Associative priming; Lexical decision; Automatic/strategic processes; Masked priming

\footnotetext{
${ }^{*}$ Corresponding author. Fax: +34-963-864697.

E-mail address: mperea@uv.es (M. Perea).

${ }^{1}$ Recipient of a pre-doctoral grant from the Spanish Ministry of Science and Culture.
} 


\section{Introduction}

A well-known fact in cognitive psychology is that a target word (e.g., CHAIR) is responded to more rapidly/accurately when it is preceded by an associatively/semantically related word (the prime, table) than when it is preceded by an unrelated word (see Moss, Ostrin, Tyler, \& Marslen-Wilson, 1995, for a recent review). In the classical "spreading activation" account, activation spreads along a lexical/semantic network, so that the prime word automatically sends activation to associatively/ semantically related words (Collins \& Loftus, 1975). Thus, the identification time of the subsequently "pre-activated" words is sped up. Although the existence of an automatic, fast acting priming effect that is independent of participants' intention appears to be well established, associative priming effects can also be subject to strategic influences.

There is currently considerable interest in distinguishing between those cognitive processes which occur automatically during reading and those which are under some level of strategic control (e.g., see Gibbs \& Van Orden, 1998; Grainger \& Jacobs, 1996; Stone \& Van Orden, 1993; Taylor \& Lupker, 2001; Zevin \& Balota, 2000). The present paper addresses this issue by manipulating the proportion of associatively related pairs when the stimulus-onset asynchrony (SOA) between prime and target is very brief. The argument is that if processing of a target word is facilitated automatically by the prior presentation of a related prime (e.g., by spreading activation to all words related to the prime), the occurrence of priming should be unaffected by the proportion of related pairs in the list. Differential priming of target words in the high- and low-proportion lists would be indicative of strategic (or attention-controlled) rather than automatic processes (Neely, 1977; Posner \& Snyder, 1975). In general, these attention-controlled processes are thought to be slow-acting and seem to occur when the SOA is relatively long (not less than $250 \mathrm{~ms}$; Neely, 1977). Indeed, when the SOA between prime and target is long (more than 400 $\mathrm{ms}$ ), there is little doubt that the magnitude of the associative/semantic priming effect increases substantially when there is a high proportion of associatively/semantically related pairs in the list (e.g., Bushell, 1996; Chwilla, Brown, \& Hagoort, 1995; de Groot, 1984; den Heyer, 1985; den Heyer, Briand, \& Dannenbring, 1983; Henik, Friedrich, Tzelgov, \& Tramer, 1994; Huttenlocher \& Janicek, 1983; Keefe \& Neely, 1990; Neely, Keefe, \& Ross, 1989; Seidenberg, Waters, Sanders, \& Langer, 1984; Stolz \& Neely, 1995; Tweedy, Lapinski, \& Schvaneveldt, 1977). When the SOA between prime and target is long and there is a high proportion of associatively related pairs, participants may try to anticipate the related target (i.e., "anticipation" strategy). If the target is one of the anticipated words, its recognition will be facilitated. Specifically, the higher the proportion of associatively related pairs is, the greater the associative priming effect will be. However, when the proportion of associatively related pairs is low - or when the SOA is too brief for an expectancy-driven mechanism to be operative - such an expectancy-driven effect is not expected to occur.

Alternatively, de Groot (1984) suggested that the relatedness proportion effect could also be due to a context-verification checking. Context-verification processes would appear when the target word has been located and its compatibility with 
the context is checked (e.g., see den Heyer, 1985; Forster, 1979, 1981; Snow \& Neely, 1987; West \& Stanovich, 1982). It is unknown as to how much time (if any) must intervene between the prime and target for a context-verification checking strategy to be used, although this check must await activation and recognition of the semantic aspects of a prime and target (see Snow \& Neely, 1987). Moreover, de Groot (1984) pointed out that this context-verification checking is relatively independent of the SOA, since it is "as effective at $240-\mathrm{ms}$ SOA as it is at the longer SOAs" ( $\mathrm{p}$. 275). The strong expectation of related pairs in a high-proportion list "may cause the decision maker to interpret all occasions on which it does not receive a yes bias from the semantic processor as information favoring a no response" (de Groot, 1984, p. 273). This no bias will slow down yes responses (and it will cause more errors) to word targets following unrelated primes. As a result, an increase in the proportion of related pairs would enhance the magnitude of the associative priming effect. Interestingly, if this mechanism only modifies decision processes occurring after lexical access has been completed, it should not appear in a naming task. In contrast, if this context-verification checking is a fundamental part of language comprehension processes (e.g., checking model, Norris, 1986), its effect should occur in different experimental tasks (e.g., lexical decision and naming).

In addition, it has been argued that both expectancy-driven and context-verification processes can be integrated in a single flexible post-lexical process ("attentional shift", see Osterhout \& Holcomb, 1995; see also Seidenberg et al., 1984). For instance, participants in the high-proportion condition do not generate a candidate set based on the expectancy of the target once they have seen the prime (since they do not have the time for this process to occur), but they expect that the prime-target pair is associatively related (see Snow \& Neely, 1987, for a similar proposal).

It is worth noting that the evidence of a relatedness proportion effect at relatively short SOAs (less than $250 \mathrm{~ms}$ ) in lexical decision is rather mixed. At a $240-\mathrm{ms} \mathrm{SOA}$, de Groot (1984) found a somewhat stronger associative priming effect for a group of participants with a high proportion of related pairs (.75) than for a group of participants with a low proportion of related pairs (.25): 74 and $5.0 \%$ vs. $58 \mathrm{~ms}$ and $4.1 \%$, respectively. The reliability of the critical interaction was not tested, though. Although the three-way interaction between relatedness, proportion, and SOA (240, 540 , and $1040 \mathrm{~ms}$ ) was significant (in the analysis by items), the Relatedness $\times$ Proportion interaction was not tested at each SOA. The three-way interaction reflected a substantial relatedness proportion effect at the 1040-ms SOA (123 vs. $59 \mathrm{~ms}$, for the high- and low-proportion conditions, respectively) and - to a lesser degree - at the 540-ms SOA (91 vs. $66 \mathrm{~ms}$, for the high- and low-proportion conditions, respectively). More recently, Stolz and Neely (1995) failed to find any signs of a relatedness proportion effect at a 200-ms SOA: The priming effects were $35 \mathrm{~ms}$ and $1.0 \%$ for the high-proportion condition, and $37 \mathrm{~ms}$ and $1.0 \%$ for the low-proportion condition. Although it might be argued that the manipulation of the proportion of related pairs was relatively weak (.25 vs. .50), Stolz and Neely found a robust relatedness proportion effect at an $800 \mathrm{~ms}$ SOA with this same manipulation. Finally, Henik et al. (1994, Experiment 3) found a significant interaction between proportion of related pairs (.20 vs. .80) and associative relatedness in the lexical decision task at a 
240-ms SOA. The priming effects were $81 \mathrm{~ms}$ and $4.5 \%$ for the high-proportion condition, and $5 \mathrm{~ms}$ and $1.8 \%$ for the low-proportion condition. It must be noted that in the Henik et al. experiment, the prime was either named or was searched for a specific letter (after lexical decision on the target), which makes it difficult to compare with a "standard" associative priming experiment. As a result, it is possible that the demands of prime processing could account for the relatedness proportion effect in the Henik et al. experiment.

To our knowledge, only a few studies have examined the presence of relatedness proportion effects at very brief SOAs (less than $150 \mathrm{~ms}$ ); den Heyer et al. (1983) failed to find a relatedness proportion effect at a $75-\mathrm{ms}$ SOA in the lexical decision task (Experiments 2 and 3). It should be noted that, in their experiments, the prime was not masked and the target was presented one line below the prime while the prime remained in view. (The fact of presenting the prime and the target on the screen at the same time might have induced some participants' strategies; however, that was not the case in the den Heyer et al. experiments.) Snow and Neely (1987) found that the magnitude of the semantic priming effect with unmasked primes at a very short SOA ( $80 \mathrm{~ms})$ was modulated by the composition of the list. Specifically, Snow and Neely manipulated the proportion of semantically related pairs and the proportion of identical pairs: when the proportion of semantically related trials was .50 and the proportion of identical pairs was .20 , the semantic priming effect was robust. However, the semantic priming effect was greatly reduced when the proportion of semantically related trials was .20 and the proportion of identical pairs was .50, which could be taken as evidence of strategic processes acting at a very short SOA.

Even though strategic processes are necessarily linked to human performance (e.g., strategic processes increase the flexibility of the information-processing system, see Stone \& Van Orden, 1993), one could argue that participants' strategies are not theoretically relevant for the study of the word identification system. In this light, a useful strategy to minimize the impact of strategic effects is to use very short SOAs (about 30-66 ms) and forward masked primes (masked priming technique; Forster, 1998; Forster \& Davis, 1984, 1991). In this technique, the priming stimulus is presented briefly just prior to the target. A forward pattern mask precedes the prime and, under these conditions, the trace of the prime is relatively inaccessible to conscious report. Since this technique is supposed to provide data free from extra-linguistic influences or participants' strategies, the obtained priming effects should not be influenced by the characteristics of the stimulus list (see Forster, 1998). Thus, increasing the proportion of associatively related pairs should not enhance the associative priming effect. However, Forster (1998) recently acknowledged that masked pseudohomophone and masked form-priming effects might be influenced by strategic factors. More specifically, Ferrand and Grainger (1996) found that masked homophone priming effects varied from facilitative to inhibitory in dependence on the type of nonword foils (the facilitative effects were found with orthographically regular nonwords, whereas the inhibitory effects were found with pseudohomophones). In addition, Forster and Veres (1998) found that form-priming effects with word primes (e.g., junction-FUNCTION) only occurred when the nonword foils were not word- 
like. Similarly, the size of the masked repetition priming effect is very small when the discrimination task is very easy (e.g., using nonword consonant strings as nonword foils; see Bodner \& Masson, 1997). Nonetheless, the characteristics of the nonword foils can influence the criteria that participants adopt for responding in the lexical decision task (e.g., participants could make their responses on the basis of global lexical activation rather than on unique word identification, which may produce a different pattern of priming effects; see Grainger \& Jacobs, 1996). As Forster (1998) pointed out, the process that underlies priming must be distinguished from the consequences of this process for the decision-making mechanism. The presence of a relatedness proportion effect with associative pairs would demonstrate the presence of strategic processes in the masked priming technique, since all the word and nonword targets would be the same in the high- and the low-proportion conditions.

The main goal of the present series of experiments is to examine whether associative priming is independent of strategic influences at very brief SOAs. As stated earlier, there are several strategic processes that could be involved in associative/ semantic priming: (i) an anticipation strategy; (ii) the use of the fact that the items are related to simplify decision making (i.e., this post-access mechanism should appear in binary tasks, such as the lexical decision task, but not in the naming task); and (iii) using the fact that prime and target are related as evidence that the selected lexical candidate must be the right one (i.e., this mechanism would be common to lexical decision and naming tasks). In Experiment 1, we manipulated the proportion of related pairs (.18 vs. .82) in a double lexical decision task (as in the experiments of Meyer \& Schvaneveldt, 1971). In this task, participants have to decide whether or not both letter strings which are presented simultaneously (one below the other) are words. The rationale for conducting Experiment 1 was to show a relatedness proportion effect in conditions optimal to find a strategy effect. Bear in mind that the recognition of each letter string should facilitate the recognition of the other: participants can use the relation between the prime and the target to help make the double lexical decision, especially when there is a high percentage of related pairs in the list. If there is an associative/semantic relation between prime and target then the decision must be yes. That is, an associative relation between the prime and the target may bias the participant towards a yes decision. Conversely, when relatedness is not present between a pair of items, this biases the participant towards a no decision.

Experiments 2 and 3 analyzed the role of the SOA and the awareness of the primes in the relatedness proportion effect. Specifically, we manipulated the proportion of related pairs (.18 vs. .82, as in Experiment 1) at the 66- and 116-ms SOAs with the masked priming technique. If the prime is not visible (as it occurs in the masked priming technique at SOAs less than $70 \mathrm{~ms}$ ), participants will be quite unaware of the existence of the prime, and then they will also be unaware of how often a related prime occurred. As a result, the priming effect should be independent of the proportion of related pairs. The value of $66 \mathrm{~ms}$ as the shortest SOA was chosen to ensure that the associative priming effect would be sizeable, since the priming effect would be very small at briefer SOAs (e.g., see Perea \& Gotor, 1997). In contrast, if the SOA is over $100 \mathrm{~ms}$, participants will be aware of the existence of the prime, and they may be able to use the fact that the prime and the target are related as a basis for 
responding in the high-proportion condition, but not in the low-proportion condition. In other words, at the 116-ms SOA, participants in the high-proportion condition may expect that the prime-target pairs are associatively related, which could induce some participants' strategies. If this is the case, increasing the proportion of related pairs could enhance the size of the associative priming. In this light, Forster and Shen (1996) indicated that prime exposures of only $100 \mathrm{~ms}$ are sufficient to initiate quite complex processing of the prime stimulus. Experiment 2 employed a lexical decision task, whereas Experiment 3 employed a naming task. If relatedness proportion effects are found in lexical decision and naming, this result would suggest that context-checking processes are due to the common lexical access process that occurs in normal silent reading. Experiment 4 is a replication of Experiment 2 at a longer SOA (166 ms). Finally, Experiment 5 employed a similar procedure to that used by den Heyer et al. (1983). The goal of Experiment 5 was to re-examine whether it was possible to obtain strategic effects at a very short SOA ( $83 \mathrm{~ms})$ when the prime is unmasked and remains in view after the target presentation.

\section{Experiment 1 (double lexical decision task)}

\subsection{Method}

\subsubsection{Participants}

A total of 52 students from introductory psychology courses at the Universitat de València took part in the experiment to earn extra course credit. All of them either had normal or corrected-to-normal vision and were native speakers of Spanish.

\subsubsection{Materials}

A set of 24 semantically related pairs of words was selected from the free association norms in Spanish (Algarabel, Sanmartín, García, \& Espert, 1986). The mean associative strength was $32 \%$ (range 13-55\%). The mean length in letters was 4.9 (range: 4-7) for the primes and 5.3 (range: 3-7) for the targets. The materials are given in Appendix A. We also selected 24 unrelated primes matched in length and word frequency with the related primes. Two stimulus lists were created by matching each of those targets with either its associated prime or an unrelated prime. That is, prime-target pairs were rotated across the priming condition and across two groups of participants (for each prime duration and proportion of related pairs) such that no participant was presented any single prime or target word more than once, but every participant received both priming conditions. In all cases, the experimental word pairs (either related or unrelated) differed in the first phoneme (see Forster \& Davis, 1991). Sixty-six word-nonword pairs were constructed for the lexical decision task. Nonwords were orthographically legal and had been constructed by changing one letter from a Spanish word other than those in the experimental set.

For the high-proportion condition, 42 filler associated prime-target pairs were added to each stimulus list (the mean associative strength was 25\%; range 9-72\%). For the low-proportion condition 42 filler unrelated prime-target pairs were added 
to each stimulus list (the targets were the same as in the high-proportion condition). Consequently, each of the two lists in the high-proportion condition included 24 critical word-word pairs (12 related, 12 unrelated), 42 filler associated word-word pairs, and 66 word-nonword pairs (i.e., the relatedness proportion was .82). Each list in the low-proportion condition included 24 critical word-word pairs (12 related and 12 unrelated), 42 filler unrelated word-word pairs, and 66 word-nonword pairs (i.e., the relatedness proportion was .18).

\subsubsection{Design}

Proportion of related pairs (high proportion, low proportion) were varied between participants (26 participants in each proportion condition), whereas associative relatedness (related, unrelated) was varied within participants. In the experimental phase, each participant was given a total of 132 trials: 66 word-word trials ( 24 critical trials and 42 filler trials) and 66 word-nonword trials.

\subsubsection{Procedure}

Participants were tested in groups of 4-10 students. Presentation of the stimuli and recording of reaction times were controlled by Apple Macintosh Classic II microcomputers. In this and the following experiments, the routines for controlling stimulus presentation and reaction time collection were obtained from Lane and Ashby (1987) and from Westall, Perkey, and Chute (1986), respectively. On each trial, two strings of lowercase letters were presented centered, one below the other. Participants were told that on each trial they would be shown a pair of letter strings (in lowercase letters), and that the task was to decide on whether the two letter strings were legitimate Spanish words or not. Participants were instructed to press one of the two buttons on the keyboard ("ç" for yes and " $z$ " for no) to indicate whether the two letter strings were words or not. This decision had to be done as quickly and as accurately as possible. When the participant responded, the two letter strings disappeared from the screen. After an inter-trial interval of $1500 \mathrm{~ms}$, the next trial was presented. On half of the trials, the target was presented below the prime and on the other half the prime was presented below the target. Each participant received a total of 20 practice trials prior to the 132 experimental trials. Each participant received a different random order of stimuli. The whole session lasted approximately $10 \mathrm{~min}$.

\subsection{Results}

Incorrect responses (1.5\%) and reaction times less than $300 \mathrm{~ms}$ or greater than $2 \mathrm{~s}$ $(1.6 \%$ of the data) were excluded from the latency analysis. Mean lexical decision latencies for correct responses and error rates were calculated across individuals and across items. Participant and item analyses of variance (ANOVAs) based on the participants' and items' response latencies and error rates were conducted based on a 2 (Associative relatedness: related, unrelated) $\times 2$ (Proportion of related pairs: $.18, .82) \times$ 2 (List: list 1, list 2) design. In this and subsequent analyses, the factor list was included as a dummy variable to extract the variance due to the error associated with 
Table 1

Mean response times (in ms), standard deviations, and error rates (\% errors) on target words in Experiment 1 (double lexical decision task)

\begin{tabular}{|c|c|c|c|c|c|c|c|}
\hline & \multicolumn{6}{|c|}{ Associative relatedness } & \multirow[t]{3}{*}{ Priming effect } \\
\hline & \multicolumn{3}{|c|}{ Related } & \multicolumn{3}{|c|}{ Unrelated } & \\
\hline & RT & SD & ER & RT & SD & ER & \\
\hline High proportion & 880 & 161 & 0.0 & 1109 & 170 & 2.6 & 229 (2.6) \\
\hline Low proportion & 876 & 101 & 1.6 & 1037 & 104 & 1.9 & $161(0.3)$ \\
\hline
\end{tabular}

the lists (see Pollatsek \& Well, 1995) and the significance level was set to $p<.05$. The mean lexical decision latencies and error rates from the participant analysis are presented in Table 1.

An ANOVA on the latency data showed that the main effect of relatedness was significant: $F 1(1,48)=266.95, \mathrm{MSE}=3805 ; F 2(1,22)=141.92$, $\mathrm{MSE}=6540$. The interaction between proportion of related pairs and relatedness was also significant: $F 1(1,48)=8.52, \mathrm{MSE}=3805 ; F 2(1,22)=5.34$, MSE $=511$ : on average, associative priming effects were $68 \mathrm{~ms}$ greater in the high-proportion condition than in the low-proportion condition.

The ANOVA on the error data showed a significant effect of relatedness: $F(1,48)=5.01, \mathrm{MSE}=10.8$. The interaction between proportion of related pairs and relatedness was marginally significant: $F(1,48)=3.03$, MSE $=10.8, p=.088$, which reflected a significant effect of relatedness for the high-proportion condition: $F(1,48)=7.92, \mathrm{MSE}=10.8$, but not for the low-proportion condition, $F<1$.

The results of this experiment are clear-cut. There was a substantial relatedness proportion effect in the double lexical decision task (both in the latency and in the error data): participants used the associative/semantic relationship between the two letter strings to make their response. Interestingly, the magnitude of the priming effect in the low-proportion condition was quite large $(161 \mathrm{~ms})$, which suggests once more - that associative priming effects appear to be automatic (i.e., the associative priming effect does not require an expectation on the part of the participants that word pairs will be related). The question now is whether or not the relatedness proportion effect occurs with a standard priming paradigm at very brief SOAs.

\section{Experiment 2 (lexical decision task: 66- and 116-ms SOAs)}

\subsection{Method}

\subsubsection{Participants}

A total of 120 psychology students from the Universitat de València took part in the experiment to earn extra course credit. All of them either had normal vision or vision that was corrected-to-normal, and were native speakers of Spanish. None of them had participated in Experiment 1. 


\subsubsection{Materials}

They were the same as in Experiment 1.

\subsubsection{Design}

SOA (66 and $116 \mathrm{~ms}$ ) and proportion of related pairs (high proportion, low proportion) were varied between participants (48 participants at the 66-ms SOA: 24 in each proportion condition, and 72 participants at the 116-ms SOA: 36 in each proportion condition), whereas associative relatedness (related, unrelated) was varied within participants. In the experimental phase, each participant was given a total of 132 trials: 66 word-word trials ( 24 critical trials and 42 filler trials) and 66 word-nonword trials.

\subsubsection{Procedure}

Participants were tested in groups of 20-24 in a quiet room. Presentation of the stimuli and recording of reaction times were controlled by Apple Macintosh Classic II microcomputers. On each trial, a forward mask consisting of a row of seven hash marks (\#\#\#\#\#\#\#) was presented for $500 \mathrm{~ms}$ on the center of the screen. Next, a lowercase prime word was presented centered for 66 or $116 \mathrm{~ms}$. Primes were immediately replaced by an uppercase target item. Participants were instructed to press one of the two buttons on the keyboard ("ç" for yes and " $\mathrm{z}$ " for no) to indicate whether the uppercase letter string was a legitimate Spanish word or not. This decision had to be done as quickly and as accurately as possible. When the participant responded, the target disappeared from the screen. Reaction times were measured from target onset until the participants' response. After an inter-trial interval of $1500 \mathrm{~ms}$, the next trial was presented. Participants at the 66-ms SOA were not informed of the presence of lowercase words. Each participant received a total of 20 practice trials (in the low-proportion condition, 20\% of the word pairs were related, whereas in the high-proportion condition, $80 \%$ of the word pairs were related) prior to the 132 trials of the experimental phase. Stimulus presentation was randomized, with a different order for each participant. The whole session lasted approximately $13 \mathrm{~min}$.

\subsection{Results}

Incorrect responses $(4.5 \%)$ and reaction times less than $300 \mathrm{~ms}$ or greater than $1300 \mathrm{~ms}(2.1 \%$ of the data) were excluded from the latency analysis. Participant and item ANOVAs based on the participants' and items' response latencies and error rates were conducted based on a 2 (SOA: 66, $116 \mathrm{~ms}) \times 2$ (Associative relatedness: related, unrelated $) \times 2$ (Proportion of related pairs: .18, .82) $\times 2$ (List: list 1, list 2) design. The mean lexical decision latencies and error rates from the participant analysis are presented in Table 2.

The ANOVA on the latency data showed that the relatedness effect was significant: $F 1(1,112)=35.99$, MSE $=1682 ; F 2(1,22)=41.78, \mathrm{MSE}=1633$. The interaction between SOA and relatedness was also significant: $F 1(1,112)=8.16$, MSE = $1682 ; F 2(1,22)=5.35, \mathrm{MSE}=2254$ : on average, the priming effect was smaller for 
Table 2

Mean response times (in ms), standard deviations, and error rates (\% errors) on target words in Experiment 2

\begin{tabular}{|c|c|c|c|c|c|c|c|}
\hline & \multicolumn{6}{|c|}{ Associative relatedness } & \multirow[t]{3}{*}{ Priming effect } \\
\hline & \multicolumn{3}{|c|}{ Related } & \multicolumn{3}{|c|}{ Unrelated } & \\
\hline & RT & SD & ER & RT & SD & ER & \\
\hline \multicolumn{8}{|l|}{$\mathrm{SOA}=66 \mathrm{~ms}$} \\
\hline High proportion & 682 & 82 & 5.4 & 692 & 80 & 5.4 & $10(0.0)$ \\
\hline Low proportion & 691 & 86 & 4.1 & 715 & 81 & 4.8 & $24(0.7)$ \\
\hline \multicolumn{8}{|l|}{$\mathrm{SOA}=116 \mathrm{~ms}$} \\
\hline High proportion & 672 & 110 & 3.9 & 725 & 109 & 6.5 & $52(2.6)$ \\
\hline Low proportion & 674 & 109 & 2.8 & 717 & 122 & 3.5 & $43(0.7)$ \\
\hline
\end{tabular}

the 66-ms SOA than for the 116-ms SOA (17 vs. $47 \mathrm{~ms}$, respectively). The other effects were not significant (all $p$ 's $>.10$ ).

The ANOVA on the error data only revealed a main effect of relatedness: $F(1,112)=7.81, \mathrm{MSE}=25.3$, in which targets preceded by related primes were responded to more accurately than those preceded by unrelated primes $(4.1 \% \mathrm{vs} .5 .1 \%$ of errors, respectively).

The results are quite straightforward. There was a reliable effect of associative priming, replicating earlier research with the masked priming technique (de Groot \& Nas, 1991; Perea \& Gotor, 1997; Rosa \& Perea, 1998; Sereno, 1991), which was stronger for the longest SOA. However, there were no clear signs of a relatedness proportion effect: at the longer SOA $(116 \mathrm{~ms})$, the associative priming effect was only a bit stronger for the high-proportion group (52 ms, 2.6\%) than for the low-proportion group (43 ms, $0.7 \%){ }^{2}$

\section{Experiment 3 (naming task: 66- and 116-ms SOAs)}

Experiment 3 tests the effect of proportion of related pairs in the naming task, using the same SOAs as in Experiment 2. To our knowledge, all the published studies using the naming task have manipulated the proportion of related pairs at long SOAs (e.g., $500 \mathrm{~ms}$, Huttenlocher and Janicek, 1985; $1000 \mathrm{~ms}$, Keefe \& Neely, 1990; $500 \mathrm{~ms}$, Seidenberg et al., 1984), which makes it difficult to isolate contextchecking processes from expectancy processes. Specifically, Huttenlocher and

\footnotetext{
${ }^{2}$ We must note that a pilot study at an $83 \mathrm{~ms}$ SOA yielded a significant relatedness proportion effect in the lexical decision task (the priming effects for the high- and the low-proportion conditions were 67 and $27 \mathrm{~ms}$, respectively). However, the substantial priming effect in the high-proportion condition was probably an empirical anomaly, since a direct replication of the experiment yielded a priming effect of 25 $\mathrm{ms}$ for the high-proportion condition. Furthermore, two more replication attempts of the experiment (for the high-proportion condition) at the same SOA - with a different set of nonword foils - yielded priming effects of 25 and $23 \mathrm{~ms}$, respectively.
} 
Janicek (1983) found stronger priming effects for a high-proportion condition than a low-proportion condition at a 500-ms SOA (although the critical interaction was not significant). Similarly, Keefe and Neely (1990) found a relatedness proportion effect at a 1000-ms SOA. However, Seidenberg et al. (1984) failed to find a relatedness proportion effect at the 500-ms SOA in the naming task, although the manipulation of this factor was relatively weak (.33 vs. .20).

\subsection{Method}

\subsubsection{Participants}

A total of 104 students from introductory psychology courses at the Universitat de València took part in the experiment to earn extra course credit. None of them had participated in the previous experiments.

\subsubsection{Materials and design}

The materials and design were the same as in Experiment 1, except that wordnonword trials were excluded. Forty-eight participants were assigned to the 66-ms SOA (24 in each proportion condition) and 56 participants were assigned to the 116-ms SOA (28 in each proportion condition). Each participant was given a total of 66 trials in the experimental phase.

\subsubsection{Procedure}

The procedure was identical to that in Experiment 1 except that participants were tested individually, and were instructed to read aloud the uppercase word as rapidly and accurately as possible. Naming latencies were collected by a microphone connected to a voice-activated key (Algarabel, Sanmartín, \& Ahuir, 1989) interfaced with a digital I/O port of an Apple Macintosh Plus microcomputer. Each participant received a total of 10 practice trials prior to the 66 experimental trials. The whole session lasted approximately $7 \mathrm{~min}$.

\subsection{Results}

Naming times less than $250 \mathrm{~ms}$ or greater than $900 \mathrm{~ms}(1.5 \%$ of the data) were excluded from the latency analysis. The mean naming latencies from the participant analysis are presented in Table 3.

The ANOVA on the latency data showed that the main effect of relatedness was significant: $F 1(1,96)=19.01, \mathrm{MSE}=326 ; F 2(1,22)=14.49, \mathrm{MSE}=441$. The main effects of proportion and SOA were significant in the analysis by items: $F 1(1,96)<$ $1 ; F 2(1,22)=9.70, \mathrm{MSE}=289$, and $F 1(1,96)<1 ; F 2(1,22)=6.08, \mathrm{MSE}=563$, respectively. The other effects were not significant (all $p$ 's $>.10$ ).

To summarize, the effect of associative relatedness was significant, replicating the recent masked priming study of Perea and Gotor (1997). Despite the fact that Spanish is a shallow language and all the stimuli can be pronounced using graphemeto-phoneme correspondences, lexical/semantic effects do occur in naming Spanish 
Table 3

Mean response times (in ms) and standard deviations on target words in Experiment 3

\begin{tabular}{|c|c|c|c|c|c|}
\hline & \multicolumn{4}{|c|}{ Associative relatedness } & \multirow[t]{3}{*}{ Priming effect } \\
\hline & \multicolumn{2}{|c|}{ Related } & \multicolumn{2}{|c|}{ Unrelated } & \\
\hline & $\mathrm{RT}$ & $\mathrm{SD}$ & $\mathrm{RT}$ & SD & \\
\hline \multicolumn{6}{|l|}{$\mathrm{SOA}=66 \mathrm{~ms}$} \\
\hline High proportion & 566 & 49 & 568 & 49 & 2 \\
\hline Low proportion & 580 & 50 & 593 & 51 & 13 \\
\hline \multicolumn{6}{|l|}{$\mathrm{SOA}=116 \mathrm{~ms}$} \\
\hline High proportion & 565 & 54 & 578 & 55 & 13 \\
\hline Low proportion & 558 & 57 & 573 & 64 & 15 \\
\hline
\end{tabular}

words (e.g., see Perea \& Carreiras, 1998). More important, as in Experiment 2, there were no signs of a relatedness proportion effect. ${ }^{3}$

The failure to find a relatedness proportion effect in Experiments 2-3 may simply indicate that the 116-ms SOA is too short for prime-induced strategic processes to be effective. In this light, Hinton, Liversedge, and Underwood (1998) found a similar pattern of facilitation for words preceded by unambiguous trigrams (wam-WARM) and by ambiguous trigrams (war-WARM; e.g., ward, ware, warn, or warp would also be consistent with the trigram war) when the (unmasked) primes were presented for $100 \mathrm{~ms}$ and when the (masked) primes were presented for $60 \mathrm{~ms}$. This finding reinforces the view that processes at an SOA of about $100 \mathrm{~ms}$ are automatic rather than strategic or, at least, that a brief SOA eliminates the kind of strategy that produces a relatedness proportion effect. A longer SOA is probably necessary for these strategic processes to have enough time to become operative.

To enhance the visibility of the primes (while keeping a very short SOA), the SOA in Experiment 4 was increased to $166 \mathrm{~ms}$. The motivation was that, under these conditions, participants could have a better chance to develop strategic effects. We used the lexical decision task, since this task is more likely to be subject to strategic influences than the naming task.

\footnotetext{
${ }^{3}$ An unexpected result that deserves some comments is the lack of a relatedness effect in the highproportion condition at the 66-ms SOA in both experimental tasks (i.e., lexical decision and naming). A closer inspection of the data for this condition reveals that only $54 \%$ of the participants showed a priming effect in the lexical decision task (there was a $10 \mathrm{~ms}$ overall effect), which was reduced to $33 \%$ in the naming task (there was a $2 \mathrm{~ms}$ overall effect). The lack of a relatedness effect in the high-proportion condition at the shortest SOA might be explained in the theoretical framework of Carr and Dagenbach (1990) and Dagenbach, Carr, and Wilhelmsen (1989). Possibly, a number of participants in the high-proportion condition became aware that some of the primes and targets could be related - in part because related targets may facilitate the processing of their corresponding primes - and then some of them could have tried to use a "retrieval strategy" for these difficult-to-see primes. On a number of trials, participants may have unsuccessfully attempted to retrieve it, causing inhibition. Of course, the previous account must be taken with caution, since the critical interaction was not significant.
} 


\section{Experiment 4 (lexical decision task: 166-ms SOA)}

\subsection{Method}

\subsubsection{Participants}

A total of 48 psychology students from the Universitat de València took part in the experiment to earn extra course credit. All of them either had normal or corrected-to-normal vision and were native speakers of Spanish. None of them had participated in the previous experiments.

\subsubsection{Materials}

The materials were the same as in Experiment 1.

\subsubsection{Design}

Proportion of related pairs (high proportion, low proportion) was varied between participants (24 participants in each proportion condition), whereas associative relatedness (related, unrelated) was varied within participants. In the experimental phase, each participant was given a total of 132 trials: 66 word-word trials ( 24 critical trials and 42 filler trials) and 66 word-nonword trials.

\subsubsection{Procedure}

The procedure was the same as in Experiment 2, except that the SOA was set to $166 \mathrm{~ms}$.

\subsection{Results}

Incorrect responses $(3.7 \%)$ and reaction times less than $300 \mathrm{~ms}$ or greater than $1300 \mathrm{~ms}(0.95 \%$ of the data) were excluded from the latency analysis. Participant and item ANOVAs based on the participants' and items' response latencies and error rates were conducted based on a 2 (associative relatedness: related, unrelated) $\times 2$ (Proportion of related pairs: .18, .82) $\times 2$ (List: list 1, list 2) design. The mean lexical decision latencies and error rates from the participant analysis are presented in Table 4.

An ANOVA on the latency data showed that the relatedness effect was significant: $F 1(1,44)=14.72, \mathrm{MSE}=1784 ; F 2(1,22)=16.35, \mathrm{MSE}=1863$. The main effect of

Table 4

Mean response times (in ms), standard deviations, and error rates (\% errors) on target words in Experiment 4 (166-ms SOA)

\begin{tabular}{|c|c|c|c|c|c|c|c|}
\hline & \multicolumn{6}{|c|}{ Associative relatedness } & \multirow[t]{3}{*}{ Priming effect } \\
\hline & \multicolumn{3}{|c|}{ Related } & \multicolumn{3}{|c|}{ Unrelated } & \\
\hline & $\mathrm{RT}$ & SD & ER & RT & $\mathrm{SD}$ & ER & \\
\hline High proportion & 668 & 104 & 2.8 & 705 & 105 & 6.9 & $37(4.1)$ \\
\hline Low proportion & 644 & 88 & 1.0 & 674 & 98 & 4.2 & $30(3.2)$ \\
\hline
\end{tabular}


proportion was significant in the analysis by items: $F 2(1,22)=7.44$, MSE $=2286$, but not in the analysis by participants: $F 1(1,44)=1.07, \operatorname{MSE}=17385, p>.15$. There were no signs of an interaction between the two factors, both $F$ 's $<1$.

An ANOVA on the error data showed that the main effect of relatedness was significant: $F(1,44)=11.09$, MSE $=28.7$, in which targets preceded by related primes were responded to more accurately than those preceded by unrelated primes (4.1 vs. $3.2 \%$ of errors, respectively). The main effect of proportion approached statistical significance: $F(1,44)=3.82, \mathrm{MSE}=31.82, p=.057$. Again, there were no signs of an interaction between the two factors, both $F$ 's $<1$.

Again, the results are quite straightforward. There was a reliable effect of associative priming, but there were no signs of a relatedness proportion effect even when the primes were clearly visible. Thus, it seems that when the SOA is very brief (less than $200 \mathrm{~ms}$ ) the effects of associative priming are independent of the proportion of associatively related pairs.

Why did we find a robust relatedness proportion effect in Experiment 1 (double lexical decision task) when both prime and target were presented simultaneously? Participants in the high-proportion condition seemed to have used the prime-target relationship as an aid to make the response. This is not surprising if we take into account that the detection of a prime-target relation clearly simplifies the decisionmaking process in a double lexical decision task. Alternatively, one could argue that the relatedness proportion effect is more likely to occur when both the prime and target remain in view; in other words, the fact of presenting the prime and the target on the screen at the same time might induce some participants' strategies. (Keep in mind that in the standard priming procedure, the prime is replaced by the target.) However, as we said in Section 1, den Heyer et al. (1983) failed to find a relatedness proportion effect in a lexical decision task when the prime was not masked and the target was presented one line below the prime while the prime remained in view (the SOA was $75 \mathrm{~ms}$ ). In fact, den Heyer et al. (1983, Experiment 3) reported a somewhat greater relatedness effect in the low-proportion condition $(30 \mathrm{~ms})$ than in the highproportion condition $(6 \mathrm{~ms})$, although the interaction was not significant. Given the strong relatedness proportion effect found in Experiment 1, we believe that it is important to further examine whether or not it is possible to obtain a relatedness proportion effect at a very short SOA $(83 \mathrm{~ms})$ when the prime is unmasked and remains in view after the target presentation.

\section{Experiment 5 (lexical decision task: unmasked primes at an 83-ms SOA)}

\subsection{Method}

\subsubsection{Participants}

A total of 44 students from introductory psychology courses at the Universitat de València took part in the experiment to fulfill a course requirement. None of them had participated in the previous experiments. 


\subsubsection{Design and materials}

The design and the materials were the same as in the previous experiments.

\subsubsection{Procedure}

The participants were tested individually or in pairs. On each trial, a lowercase prime word was presented centered for $83 \mathrm{~ms}$, and then the uppercase target was presented below the prime, which remained in view. Nonetheless, to induce the participants to process both the prime and the target, on $15 \%$ of the filler trials in each phase (either word-word filler trials or word-nonword trials) the uppercase target was presented for $83 \mathrm{~ms}$, and immediately the prime (in lowercase) was presented below the target, which remained in view. Participants were instructed to press one of the two buttons on the keyboard ("ç" for yes and " $z$ " for no) to indicate whether the uppercase letter string was a legitimate Spanish word or not. This decision had to be done as quickly and as accurately as possible. When the participant responded, the prime and the target disappeared from the screen. After an inter-trial interval of 1500 ms, the next trial was presented. Each participant received a total of 20 practice trials prior to the 132 experimental trials. The whole session lasted approximately $11 \mathrm{~min}$.

\subsection{Results}

Incorrect responses $(3.5 \%)$ and reaction times less than $300 \mathrm{~ms}$ or greater than $1300 \mathrm{~ms}$ (less than $2.5 \%$ of the data) were excluded from the latency analysis. The mean lexical decision time and the error rate on the stimulus words in each experimental condition are shown in Table 5.

The ANOVA on the latency data showed that the main effect of relatedness was marginally significant: $F 1(1,40)=3.24, \mathrm{MSE}=1849, p<.071 ; F 2(1,22)=3.17$, $\mathrm{MSE}=3563, p<.089$. The effect of proportion of related pairs was not significant, both $F$ 's $<1$. The effect of associative relatedness was only slightly greater in the high-proportion condition than in the low-proportion condition (19 vs. $14 \mathrm{~ms}$ ), as reflected by the lack of a significant interaction between the proportion of related pairs and the size of the priming effect, both $F$ 's $<1$.

The ANOVA on the error data only showed a significant effect of associative priming: $F 1(1,40)=4.19, \mathrm{MSE}=31.9$.

Table 5

Mean response times (in ms), standard deviations, and error rates (\% errors) on target words in Experiment 5 (83-ms SOA with visible primes)

\begin{tabular}{|c|c|c|c|c|c|c|c|}
\hline & \multicolumn{6}{|c|}{ Associative relatedness } & \multirow[t]{3}{*}{ Priming effect } \\
\hline & \multicolumn{3}{|c|}{ Related } & \multicolumn{3}{|c|}{ Unrelated } & \\
\hline & $\mathrm{RT}$ & $\mathrm{SD}$ & ER & RT & $\mathrm{SD}$ & ER & \\
\hline High proportion & 699 & 109 & 1.5 & 718 & 98 & 3.8 & $19(2.3)$ \\
\hline Low proportion & 690 & 95 & 3.1 & 704 & 112 & 5.7 & $14(2.6)$ \\
\hline
\end{tabular}


As it occurred with the den Heyer et al. (1983) study, the associative priming effect was not accompanied by a reliable effect of the proportion of related pairs. Despite the fact that the current experiment shared many characteristics with Experiment 1 (double lexical decision experiment), participants in the high-proportion condition did not use the prime-target relationship as an aid to make the response. In any event, it is worth noting that the magnitude of the associative priming effect in the latency analysis $(16.5 \mathrm{~ms})$ was similar to that of the masked priming experiment in Experiment 2 (17 ms at the 66-ms SOA) and with that obtained in the den Heyer et al. (1983) study (18 ms when averaged the high- and low-proportion conditions in Experiment 3).

The results of Experiment 5 suggest that the visibility of the prime is not critical; rather it is the short SOA that matters. But then, why did we find a relatedness proportion effect with the double lexical decision task? After all, as an anonymous reviewer pointed out, the interval between the onset of the prime and the onset of the target in Experiment 1 (double lexical decision) was $0 \mathrm{~ms}$. But appearances may be deceiving. It is very likely that the effective SOA in Experiment 1 was longer than the values used in the other experiments because participants probably spend a bit of time with whichever word they happen to read first before moving onto the other word. In other words, in the double lexical decision task there is no control on the SOA. In contrast, with the den Heyer et al. (1983) technique, it is likely that participants move their attention to the targets once they are presented on the computer screen: the appearance of the target draws attention from processing of the prime.

If this reasoning is correct, when participants are induced to pay more attention to the primes in the den Heyer's technique, the effective SOA should be longer than in Experiments 2-4 - note that this would slow down lexical decision times - and then the magnitude of the associative priming effects should increase substantially. This is what we examined in a follow-up experiment. The instructions were the same as in the present experiment, with the following paragraph added: "Important note: On many trials, the lowercase word is related with the string of letters in uppercase (e.g., white-BLACK) so that this information can help you make the lexical decision for the string of letters in uppercase". Only the high-proportion condition was tested with these instructions, since knowledge of the relationship between the target and the prime can be used to aid responding. As expected, the priming effect in this follow-up experiment (63 ms, 4.4\%; related condition: $734 \mathrm{~ms}, 0.8 \%$; unrelated condition: $797 \mathrm{~ms}, 5.2 \%$ of errors) was substantially larger than in Experiment 5. Not surprisingly, participants made their responses more slowly in this follow-up study than in Experiment 5, which suggests that participants, on a number of trials, were processing the prime before shifting their attention to the target.

\section{General discussion}

The main findings of the present experiments can be summarized as follows: (1) reliable associative priming effects were found in both lexical decision and naming 
with the masked priming technique and a low proportion of related pairs, which reinforces the view that associative priming occurs automatically (e.g., de Groot \& Nas, 1991; Lukatela \& Turvey, 1994; Perea \& Gotor, 1997; Sereno \& Rayner, 1992); (2) the effect of proportion of related pairs does not seem to influence the magnitude of the associative priming effect in lexical decision and naming at very short SOAs.

Taken together, the results suggest that the masked priming technique minimizes the influence of strategic factors in visual word recognition. Nonetheless, it is important to note that masking the prime (i.e., the visibility of the prime) does not seem to be the key factor for the lack of a proportionality effect. Instead, the key factor seems to be the use of a prime-target SOA, since we failed to obtain a reliable effect of proportion of related pairs with visible primes at the 116- and 166-ms SOAs (Experiments 2-4). Only when participants were instructed to make lexical decisions on pairs of letter strings (double lexical decision task) did we find a substantial relatedness proportion effect (Experiment 1). This is not surprising, because in the double lexical decision task participants must await activation and recognition of the semantic aspects of a prime and target to make an accurate response and, thereby, the decision-making process could be simplified in the high-proportion condition. Further, as we said earlier, the effective SOA in the double lexical decision task was probably longer than the values used in the other experiments, because participants probably spend some time with whichever word they happen to read first before moving on to the other word.

It is not surprising that the proportion of related pairs does not have an effect on the $66 \mathrm{~ms}$ SOA with the masked priming technique. After all, la raison d'être of this technique is that "it offers a method for studying processing effects that might be free of extra-linguistic influences" (Forster, 1998, pp. 204-205). Interestingly, the present results failed to find any signs of any participants' strategies when the word and nonword targets were the same for all participants, which is consistent with the automatic nature of the obtained effects in the masked priming technique. As stated in Section 1, there is evidence that shows that masked homophone/repetition/formpriming effects can be affected by the characteristics of the nonword foils (e.g., Bodner \& Masson, 1997; Ferrand \& Grainger, 1996; Forster and Veres, 1998). However, the characteristics of the nonword foils probably influence the criteria for making the lexical decision responses rather than the process that underlies priming (see Ferrand \& Grainger, 1996; Forster, 1998). In other words, strategic control may reflect adjustments of task-specific response criteria on the basis of the characteristics of the word/nonword discrimination (Ferrand \& Grainger, 1996).

In addition, there were no clear signs of a relatedness proportion effect with visible primes (at the 116- and the 166-ms SOAs). However, can we accept the null hypothesis? Although accepting the null hypothesis is a tricky issue (Frick, 1995), the magnitude of the (nonsignificant) relatedness proportion effect was quite small ( 8 and $7 \mathrm{~ms}$ in the lexical decision task at the 116- and the 166-ms SOAs, respectively). One might argue that the design could have been more powerful if proportion had been a within-subjects factor. However, in an unpublished project, we have also failed to find any signs of a relatedness proportion effect in a series of lexical decision 
experiments at very short SOAs (66 and $83 \mathrm{~ms}$ ) with a within-subjects design. In the present series of experiments, we chose proportion as a between-subjects factor because priming effect could be confounded with practice effects (if participants had participated a second time; see de Groot, 1984). Furthermore, there is the possibility that the priming effect was modulated by task order, so that the magnitude of the priming effect might differ across the different blocks (e.g., see Henik et al., 1994, for a demonstration of this effect). In any event, our design was powerful enough to detect the presence of a relatedness proportion effect in Experiment 1.

As we said in Section 1, there are two reports of a significant effect of the proportion of associatively related pairs at short SOAs (Henik et al., 1994; Snow \& Neely, 1987). However, these experiments might have been influenced by processes other than automatic for several reasons. Firstly, SOA was a within-subjects factor in the design, and participants were presented the items at a short SOA and a very long SOA in the same block (an $840 \mathrm{~ms}$ SOA in the Henik et al. study; and a $1000 \mathrm{~ms}$ SOA in the Snow and Neely experiments), which might have induced some strategic processes (see Smith, Besner, \& Miyoshi, 1994, for a demonstration of this effect). (In fact, Experiment 5 shows that participants may process the primes in very different ways according to the instructions.) In contrast, the experiments that failed to obtain a relatedness proportion effect (den Heyer et al., 1983; Stolz \& Neely, 1995) used different groups of participants at each SOA. With respect to the experiment of de Groot (1984), she also used a between-subjects design and it remains to be seen whether the obtained 16-ms relatedness proportion effect ( 75 and $58 \mathrm{~ms}$ for the highand the low-proportion conditions, respectively) at the 240-ms SOA was significant.

Secondly, we should note that Snow and Neely (1987) did not just manipulate the proportion of semantically related pairs. They also manipulated - at the same time the proportion of identical trials (see Section 1). Snow and Neely suggested that when the proportion of identical trials was very high - and, consequently, the proportion of semantically related trials was very low - word responses could be based in part on only shallow preliminary processing of stimuli, attending to nominal rather than semantic aspects of the target word. With respect to the Henik et al. (1994) experiment, the prime was either named or was searched for a specific letter (after lexical decision on the target), which makes it difficult to compare with the "standard" priming experiment. Henik et al. (1994, p. 165) acknowledged that the demands of prime processing could account for the relatedness proportion effect in their experiment. As a result, the previous empirical evidence for a relatedness proportion effect at short SOAs is not entirely convincing.

In sum, the present experiments have shown that the use of the standard priming procedure at a very brief SOA seems to prevent strategic effects from being operative (at least on the basis of associative pairs): ${ }^{4}$ the magnitude of the associative priming effect was similar when the participants had a high or a low proportion of associa-

\footnotetext{
${ }^{4}$ It is worth noting that Bodner and Masson (2001) recently obtained an effect of proportion of identity primes on the magnitude of the masked repetition priming effect in a lexical decision task, although this proportionality effect only seems to occur under some circumstances.
} 
tively related pairs in the list (Experiments 2-4). Thus, the participant's awareness of the relationship between the prime and target does not seem to be critical to the relatedness proportion effect in the standard priming procedure. Specifically, it seems that participants do not have strategic control over the type of mechanism responsible for the relatedness proportion effect when the SOA is very short (see Neely \& Keefe, 1989, for a similar account). Nonetheless, it is important to examine whether it is possible to maximize the chances of obtaining a relatedness proportion effect at very brief SOAs. For instance, if specific and insisting details about the existence of related pairs are included in the instructions, the magnitude of the associative priming effect might increase substantially. However, even if a relatedness proportion effect is obtained under these circumstances, the effective SOA would probably be longer than the value specified, because participants would actively keep processing the prime after the target presentation - note that this strategy would produce longer response times. In addition, it could be argued that degrading the targets could optimize the chances of obtaining a relatedness proportion effect at a short SOA, since participants would be more likely to use the associative/semantic information from the prime in the high-proportion condition. However, Stolz and Neely (1995) failed to obtain a proportionality effect in a semantic priming experiment at a $200 \mathrm{~ms}$ SOA when comparing bright (nondegraded) and dim (degraded) stimuli (not surprisingly, responses were over $100 \mathrm{~ms}$ slower for dim than for bright targets). Perhaps, a more extreme manipulation of target degradation is necessary for the relatedness proportion effect to occur at a brief SOA.

\section{Acknowledgements}

We would like to thank Gezinus Wolters and two anonymous reviewers for very helpful comments on previous versions of the paper.

\section{Appendix A. Critical word-word pairs}

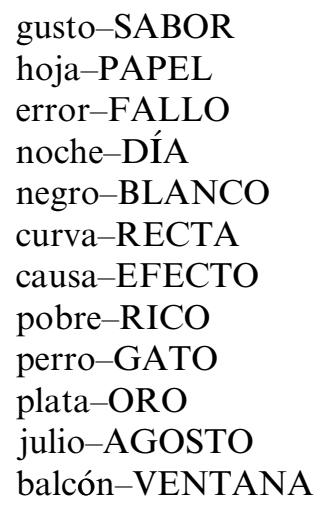

(taste-FLAVOR)

(sheet-PAPER)

(error-MISTAKE)

(night-DAY)

(black-WHITE)

(curve-STRAIGHT)

(cause-EFFECT)

(poor-RICH)

(dog-CAT)

(silver-GOLD)

(July-AUGUST)

(balcony-WINDOW) 


\author{
cara-ROSTRO \\ país-NACIÓN \\ joven-VIEJO \\ éxito-FRACASO \\ calor-FRÍO \\ verdad-MENTIRA \\ suma-RESTA \\ mesa-SILLA \\ francés-INGLÉS \\ loco-CUERDO \\ hijo-PADRE \\ frase-ORACIÓN
}

\author{
(visage-FACE) \\ (country-NATION) \\ (young-OLD) \\ (success-FAILURE) \\ (heat-COLD) \\ (true-LIE) \\ (sum-SUBTRACTION) \\ (table-CHAIR) \\ (French-ENGLISH) \\ (crazy-SANE) \\ (son-FATHER) \\ (phrase-SENTENCE)
}

\section{References}

Algarabel, S., Sanmartín, J., \& Ahuir, F. (1989). A voice-activated key for the Apple Macintosh computer. Behavior Research Methods, Instruments, and Computers, 21, 67-72.

Algarabel, S., Sanmartín, J., García, J., Espert, R. (1986). Normas de asociación libre de 400 sustantivos pertenecientes a BASPAL (Norms of free association for 400 nouns in the BASPAL lexical database). Informes del Departamento de Psicología Experimental, Universitat de València, Spain.

Bodner, G. E., \& Masson, M. E. J. (1997). Masked repetition priming for words and nonwords: Evidence for a nonlexical basis for priming. Journal of Memory and Language, 37, 268-293.

Bodner, G. E., Masson, M. E. J. (2001). Prime validity affects masked repetition priming: Evidence for an episodic resource account of priming. Journal of Memory and Language, 45, 616-647.

Bushell, C. M. (1996). Dissociated identity and semantic priming in Broca's aphasia: How controlled processing reduces inhibitory semantic priming. Brain and Language, 55, 264-288.

Carr, T. H., \& Dagenbach, D. (1990). Semantic priming and repetition priming from masked words: Evidence for a center-surround attentional mechanism in perceptual recognition. Journal of Experimental Psychology: Learning, Memory, and Cognition, 16, 341-350.

Collins, A. M., \& Loftus, E. F. A. (1975). A spreading-activation theory of semantic processing. Psychological Review, 82, 407-428.

Chwilla, D. J., Brown, C. M., \& Hagoort, P. (1995). The N400 as a function of the level of processing. Psychophysiology, 32, 274-285.

Dagenbach, D., Carr, T. H., \& Wilhelmsen, A. (1989). Task-induced strategies and near-threshold priming: Conscious influences on inconscious perception. Journal of Memory and Language, 28, 412-443.

de Groot, A. M. B. (1984). Primed lexical decisions: Combined effects of the proportion of related primetarget pairs and the stimulus-onset asynchrony of prime and target. Quarterly Journal of Experimental Psychology, 36A, 253-280.

de Groot, A. M. B., \& Nas, G. L. J. (1991). Lexical representation of cognates and noncognates in compound bilinguals. Journal of Memory and Language, 30, 90-123.

den Heyer, K. (1985). On the nature of the proportion effect in semantic priming. Acta Psychologica, 60, 25-38.

den Heyer, K., Briand, K., \& Dannenbring, G. L. (1983). Strategic factors in a lexical-decision task: Evidence for automatic and attention-driven processes. Memory and Cognition, 11, 374-381.

Ferrand, L., \& Grainger, J. (1996). List context effects on masked phonological priming in the lexical decision task. Psychonomic Bulletin and Review, 3, 515-519.

Forster, K. I. (1979). Levels of processing and the structure of the language processor. In W. E. Cooper, \& E. C. T. Walker (Eds.), Sentence processing (pp. 27-85). Hillsdale, NJ: Erlbaum.

Forster, K. I. (1981). Priming and the effects of sentence and lexical contexts on naming time: Evidence for autonomous lexical processing. Quarterly Journal of Experimental Psychology, 33A, 465-495. 
Forster, K. I. (1998). The pros and cons of masked priming. Journal of Psycholinguistic Research, 27, 203-233.

Forster, K. I., \& Davis, C. (1984). Repetition priming and frequency attenuation in lexical access. Journal of Experimental Psychology: Learning, Memory, and Cognition, 10, 680-698.

Forster, K. I., \& Davis, C. (1991). The density constraint on form-priming in the naming task: Interference from a masked prime. Journal of Memory and Language, 30, 1-25.

Forster, K. I., \& Shen, D. (1996). No enemies in the neighborhood: Absence of inhibitory effects in lexical decision and categorization. Journal of Experimental Psychology: Learning, Memory, and Cognition, 22, 696-713.

Forster, K. I., \& Veres, C. (1998). The prime lexicality effect: Form-priming as a function of prime awareness, lexical status, and discrimination difficulty. Journal of Experimental Psychology: Learning, Memory, and Cognition, 24, 498-514.

Frick, R. W. (1995). Accepting the null hypothesis. Memory and Cognition, 23, 132-138.

Gibbs, P., \& Van Orden, G. C. (1998). Pathway selection's utility for control of word recognition. Journal of Experimental Psychology: Human Perception and Performance, 24, 1162-1187.

Grainger, J., \& Jacobs, A. M. (1996). Orthographic processing in visual word recognition: A multiple readout model. Psychological Review, 103, 518-565.

Henik, A., Friedrich, F. J., Tzelgov, J., \& Tramer, S. (1994). Capacity demands of automatic processes in semantic priming. Memory and Cognition, 22, 157-168.

Hinton, J., Liversedge, S. P., \& Underwood, G. (1998). Neighborhood effects using a partial priming methodology: Guessing or activation? Journal of Experimental Psychology: Learning, Memory, and Cognition, 24, 1294-1305.

Huttenlocher, J., \& Janicek, L. F. (1983). The source of relatedness effects on naming latency. Journal of Experimental Psychology: Learning, Memory, and Cognition, 9, 486-496.

Keefe, D. E., \& Neely, J. H. (1990). Semantic priming in the pronunciation task: The role of prospective prime-generated expectancies. Memory and Cognition, 18, 289-298.

Lane, D. M., \& Ashby, B. (1987). PsychLib: A library of machine language routines for controlling psychology experiments on the Apple Macintosh computer. Behavior Research Methods Instruments and Computers, 19, 246-248.

Lukatela, G., \& Turvey, M. T. (1994). Visual lexical access is initially phonological: 1. Evidence from associative priming by words, homophones, and pseudohomophones. Journal of Experimental Psychology General, 123, 107-128.

Meyer, D. E., \& Schvaneveldt, R. W. (1971). Facilitation in recognizing pairs of words: Evidence of a dependence between retrieval operations. Journal of Experimental Psychology, 90, 227-234.

Moss, H. E., Ostrin, R. K., Tyler, L. K., \& Marslen-Wilson, W. D. (1995). Accessing different types of lexical semantic information. Journal of Experimental Psychology: Learning Memory and Cognition, $21,863-883$.

Neely, J. H. (1977). Semantic priming and retrieval from lexical memory: Roles of inhibitionless spreading activation and limited-capacity attention. Journal of Experimental Psychology: General, 106, 226-254.

Neely, J. H., \& Keefe, D. E. (1989). Semantic context effects on visual word processing: A hybrid prospective-retrospective processing theory. In H. G. Bower (Ed.), The psychology of learning and motivation: advances in research and theory (Vol. 24) (pp. 207-248). New York: Academic Press.

Neely, J. H., Keefe, D. E., \& Ross, K. L. (1989). Semantic priming in the lexical decision task: Roles of prospective prime-generated expectancies and retrospective semantic matching. Journal of Experimental Psychology: Learning, Memory, and Cognition, 15, 1003-1019.

Norris, D. (1986). Word recognition: Context effects without priming. Cognition, 22, 93-136.

Osterhout, L., \& Holcomb, P. J. (1995). Event-related potentials and language comprehension. In M. D. Rugg, \& M. G. H. Coles (Eds.), Electrophysiology of mind (pp. 171-215). Oxford: Science Publisher.

Perea, M., \& Carreiras, M. (1998). Effects of syllable frequency and neighborhood syllable frequency in visual word recognition. Journal of Experimental Psychology: Human Perception and Performance, $24,1-11$.

Perea, M., \& Gotor, A. (1997). Associative and semantic priming effects occur at very short SOAs in lexical decision and naming. Cognition, 67, 223-240. 
Pollatsek, A., \& Well, A. (1995). On the use of counterbalanced designs in cognitive research: A suggestion for a better and more powerful analysis. Journal of Experimental Psychology: Learning, Memory, and Cognition, 21, 785-794.

Posner, M. I., \& Snyder, C. R. R. (1975). Attention and cognitive control. In R. Solso (Ed.), Information processing and cognition: The Loyola symposium (pp. 55-83). Hillsdale, NJ: Erlbaum.

Rosa, E., \& Perea, M. (1998). Facilitación asociativa para palabras, pero no para pseudopalabras, con la técnica de presentación enmascarada del estímulo-señal [Associative priming effects for words, but not for nonwords, with the masked priming technique]. Psicológica, 19, 295-309.

Seidenberg, M. S., Waters, G. S., Sanders, M., \& Langer, P. (1984). Pre- and postlexical loci of contextual effects on word recognition. Memory and Cognition, 12, 315-328.

Sereno, J. A. (1991). Graphemic, associative, and syntactic priming effects at a brief stimulus onset asynchrony in lexical decision and naming. Journal of Experimental Psychology: Learning, Memory, and Cognition, 17, 459-477.

Sereno, S. C., \& Rayner, K. (1992). Fast priming during eye fixations in reading. Journal of Experimental Psychology: Human Perception and Performance, 18, 173-184.

Smith, M. C., Besner, D., \& Miyoshi, H. (1994). New limits to automaticity: Context modulates semantic priming. Journal of Experimental Psychology: Learning Memory and Cognition, 20, 104-115.

Snow, N., Neely, J. H. (1987). Reduction of semantic priming from inclusion of physically or nominally related prime-target pairs. Paper presented at the 28th Annual Meeting of the Psychonomic Society, Seattle, WA.

Stolz, J., \& Neely, J. H. (1995). When target degradation does and does not enhance semantic context effects in word recognition. Journal of Experimental Psychology: Learning, Memory, and Cognition, $21,596-611$.

Stone, G. O., \& Van Orden, G. C. (1993). Strategic control of processing in visual word recognition. Journal of Experimental: Psychology, Human Perception, and Performance, 19, 744-774.

Taylor, T., \& Lupker, S. J. (2001). Sequential effects in naming: A time criterion account. Journal of Experimental Psychology: Learning, Memory, and Cognition, 27, 117-138.

Tweedy, J. R., Lapinski, R. H., \& Schvaneveldt, R. W. (1977). Semantic-context effects on word recognition: Influence of varying the proportion of items presented in an appropriate context. Memory and Cognition, 5, 84-99.

West, R. F., \& Stanovich, K. E. (1982). Source of inhibition in experiments on the effect of sentence context on word recognition. Journal of Experimental Psychology: Learning, Memory, and Cognition, $5,385-399$.

Westall, R., Perkey, M. N., \& Chute, D. L. (1986). Accurate millisecond timing on the Apple Macintosh using Drexler's Millitimer. Behavior Research Methods Instruments and Computers, 18, 307-311.

Zevin, J. D., \& Balota, D. A. (2000). Priming and attentional control of lexical and sublexical pathways during naming. Journal of Experimental Psychology: Learning, Memory, and Cognition, 26, 121-135. 